\title{
Psychological aspects of security culture development for modern students
}

\author{
Tatyana Shcherbakova ${ }^{1 *}$, Dynamutdin Misirov $^{2}$, Marina Hakobyan ${ }^{2}$, Inna Zhitnaya ${ }^{2}$ \\ ${ }^{1}$ Rostov Institute of Advanced Studies and retraining of education workers \\ ${ }^{2}$ South Federal University, Rostov-on-Don, 344006, Russia
}

\begin{abstract}
The article considers the problem of the psychological safety development of students in the modern multicultural educational space of the university. It is shown that psychological safety is an important determining factor of the successful socialization for young people. The paper focuses on the idea that the need to create and implement in practice higher education a productive model of multicultural interaction and mutual influence among students as the most dynamic group of contemporary social activity is being actualized.Within the multicultural space of the university, as a socio-psychological, educational and vocational environment, there is an exchange of products of design, club, volunteer and research activities, experience of entering into various social communities, information, translation of professional competencies is carried out, updated and a complex of sociogenic needs is being met, settings and standards are being formed, moral standards governing the relationship of education subjects, representatives of different ethnic groups.
\end{abstract}

\section{Introduction}

The multicultural educational environment today is the most important sphere of socialization for a developing personality, being a systemic element of the socio-cultural space, including a combination of traditions, educational models and paradigms, determined historical situations, a system of specially organized psychological and pedagogical conditions for student self-identity development. In this context, in the $21 \mathrm{st}$ century, research in the field of psychology and pedagogy addresses the problem of the multicultural educational environment of the university as a factor of the psychological well-being for teachers, students, society as a whole.

In the modern world, with a pronounced tendency towards globalization and integration, the educational environment must comply with the main principle of education: "cultural compatibility", according to which education is carried out in the context of culture, focused on its values, on the achievements' assimilation, on the socio-cultural norms appropriation and orientation towards further progressive development (Shabaev, 2018)

The purpose of the research is to study the characteristics of the attitude to terrorism and extremism among students of different regions (for example, Rostov-on-Don and Makhachkala).

\footnotetext{
*Corresponding author: tatiananik@list.ru
} 
During the implementation of the empirical research program, a questionnaire was conducted to determine a number of attitude parameters toward terrorism and the content of students' perceptions about the nature of the risks associated with extremism and terrorism.

It is important to emphasize that the psychologically safe, "cultural-like" educational environment of higher education contributes to the ethno-cultural competence development of the individual, increases its mediative abilities, and forms ethnic and civic identities (Borisenkov, 2006; Vasilieva, 2008).

"Safety culture", "psychological safety" concepts today are increasingly becoming the subject of research in psychology. A number of substantial characteristics of these phenomena are distinguished: the constructive functioning of the subject as a carrier of individuality, a high level of adaptability in the context of social interaction at the university space; continuous personal and professional growth; the development of personality competence in the context of interaction with various environments; resource capabilities and formed personality abilities to diagnose, minimize and prevent risks; the ability to create and maintain psychologically safe interaction with different communication entities; tolerance and with respect to the other, the ability to simultaneously exhibit critical thinking of the incoming information estimate (Bykhovets, 2019; Dymova 2015; Padun, 2019).

The fundamental condition for maintaining the psychological safety of the university educational environment in a multicultural world can be the "cross-cultural competence" of a higher education teacher, which implies an understanding of the culture, various ethnic groups represented in the university, knowledge of its specifics, an understanding of the mentality and a positive attitude towards their representatives (Siraeva, 2009)

The cross-cultural competence of a higher education teacher allows saturating the sociocultural space of education at a university with those interaction models that can help students develop the ability to reflect as the basis for understanding the values of their own culture and the culture of other nations, and the ability to build constructive intercultural interaction in solving educational, professional and social problems.

Today, psychological and pedagogical science has a specific goal of creating and putting into practice a productive model of interethnic interaction and mutual influence among students as the currently most dynamic group at the modern social space (Podymova, 2018).

In the framework of state policy at different levels, it is emphasized that student youth acts as a real social force, a strategic resource for the development of society; teams of hyperactive users of the information network, thus being able to exert a certain influence on the public consciousness and current events. The analysis shows that the problem of ethnic socialization of the young generation has long attracted the attention of researchers in the field of psychology.

At the same time, the ethnic aspects of socialization at the stage of vocational training at a university, the influence of ethnic factors on the image development of the world, and semantization models of students' value orientations behavior were practically not considered in psychological researches.

Safe multicultural modeling of university educational space is a rather complicated problem, but it is undoubtedly resource and perspective. Moreover, through the implementation of various kinds of projects, students themselves develop implicit models of effective multicultural communication: communication on the Internet, public youth organizations, internships, educational tourism, and joint implementation of grants. From the standpoint of scientists, thr positive image development of the world, an ethnic picture of the world embedded with the students' overall worldview system, undoubtedly contributes to an increase in the level of safety culture (Borisenkov, 2006). 
The subjective image of the world as a component of the internal control system has a significant impact on the social activity of the student, setting a specific moral format. The most important role in this process is played by sign systems of various kinds: the language of symbols, professional genres, the system of images, languages of different cultures (Shabaev, 2009). By mastering various sign systems, the student expands his consciousness, thereby increasing the psychological readiness for productive interaction in a multicultural environment. These methodological positions allow us to talk about the possibility of single multicultural educational space development at university with a high security status.

In the framework of active positive transformations for the system of higher professional education in Russia, major attention is paid to the development of multiculturalism, which has a certain impact on the multifaceted holistic picture development of the world that allows a young person to adapt successfully to the requirements of life in the modern world. Humanism, civic identity, tolerance, empathy, social competence, and intolerance to any manifestations of extremism, aggression and terrorism, orientation to productive cooperation are indicators of a multicultural personality. Here, the ability of students for prediction and self-regulation plays an important role, which contributes to the development of psychological safety. Self-regulation, in turn, depends on motivation, life strategy, self-attitude, self-esteem, locus of control, personal anxiety, level of claims, self-confidence, value orientations of a person (Harlamenkova, 2019).

For a student developing in the multicultural educational space of the university, a high level of ethno-cultural communication competence is important, in which the selfregulation component is expressed, which makes it possible to form socially desirable stereotypes, expand the repertoire of student interaction models, and minimize the risks of interaction in the multicultural environment of the university (Rail, 2019)

The development of a competent communication style for students in a multicultural space involves the tolerance development, the adequacy of social perception, communicative competence and self-confidence, trust in oneself and the world, but it does not boil down to being protected from physical influences, and above all, protecting a person from manifestations of psychological aggression, negative, emotional, informational, organizational influences (Kharlamenkova, 2019). Psychological and pedagogical research, reflecting the problem of security at the university educational space, actualizes the need to study objective factors, features of a multicultural environment, attitudes of students that can influence constructively or destructively the psychological tonality and well-being of interaction. The psychological safety of the university multicultural environment ensures the psychological well-being of its subjects (Harlamenkova, 2018).

\section{Research Methods and Methodologies}

The empirical basis of the research is the data analysis collected in Dagestan (Makhachkala) and Rostov-on-Don. The sample included 102 people with differentiation by place of residence at the age of 17-24 years.

Research methods: "Questionnaire of the terrorist threat experience (QTTE-21)" (Y.V. Bykhovets, N.V. Tarabrina, N.N. Bakuseva); The scale of the individual hierarchy of value orientations (M. Rokich); "Test of meaning-life orientations" (adapted by D.A. Leontyev of the test "Purpose in life" (PIL - PurposeinLife) by J. Crambo and L. Makholik); The methodology for determining the level of subjective control (LSC) (J. Rotter, adapted by E.F. Bazhin, E.A. Golynkin and A.M. Etkind). 


\section{Research results}

The analysis of comparative data of terminal values shows that while such values as "creativity" (1), "beauty" (2) and "pleasure" (3) are of great importance for students in Rostov-on-Don city, then "freedom" becomes the main thing for students in Makhachkala "(1),"confidence" (2) and "recognition"(3).

The dynamic changes of modern socio-reality are also reflected in the content of value orientations structure, value preferences are also influenced by those landmarks that are broadcast in society, as well as ethnic stereotypes, events of history and nowadays, trends of the current situation at the region.

Obviously, the data obtained are not random, because today in Rostov region the priority of personality creative manifestations is persistently affirmed; substantial support is given to creative initiatives and projects, large array of creative spaces. A great place in the life of young people is the desire for beauty and the opportunity to have fun.

With regard to the youth of Makhachkala city, the chosen values of freedom and confidence of recognition as priority values undoubtedly reflect the characteristics of family national upbringing, certain ethnic attitudes, and in a certain sense are a projection of modern trends in the society development.

According to data analysis, "love" (16), "happiness of friends" (17) is in the last place and "health" (18) is in the last place in Rostov-on-Don and, accordingly, for Makhachkala: "love (16), "happiness of family life"(17) and, in the last place, "health "(18).

An interesting fact is the leveling by students of the value of health, obviously, this is explained by the peculiarities of worldview in adolescence. At this stage of life, as a rule, a person feels himself "strong", "athletic," and he has little interest in health problems. The assignment of a low rank of "love" value is quite unexpected, however, this can be explained by the fact that at this age this value is perceived as a given, immutable attribute, while youth makes great demands on this feeling. As for the happiness of others, maximalism and egocentrism of modern youth are probably reflected here.

In the 18th place there is "intolerance", "high demands" (17) and in the 16th place there is "efficiency". As for the analysis of students" data for Makhachkala, "high demands" is ranked 18th (18), "intolerance" is 17 th and "breadth of views" takes the 16th place. The results are "Education" (1), "firm will" (2) and "accuracy" (3).

The meaning-life orientations were studied by D.A. Leontev's method, "Test of meaning-life orientations", which is a modification of the test "Purpose in Life" (PIL Purpose in Life) by J. Crambo and L. Makholik. The results obtained during the application of the test demonstrate the severity of the general indicator of meaningfulness for life. The level of specific meaningful life orientations development for the control locus and the controllability degree of life events was achieved.

According to the Sense of life orientation (SLO) test, the level of meaningfulness of life is determined by the presence of certain and clear goals, satisfaction from their achievement and confidence in one's own ability to set desired goals, shape and achieve results.

In the context of the research problems, this technique seems quite informative. At the same time, the data obtained allow us to draw up a certain psychological portrait of students.

It is interesting that the results obtained in the course of the research show that there are practically no special differences between the meaning-life orientations of students for the Republic of Dagestan and the Rostov region.

1. The subscale "Purpose in life" of students from Dagestan (29.71) shows a change in the direction of increase than the Rostov region (28.57).

2. The subscale "Process in life" shows a change in the direction of increase than the Rostov region (29.49) versus 27.68 for students from Makhachkala. 
3. The subscale "Life Result" data results are equal to 23.92 .

4. The subscale "Locus control - I" indicators coincide - 19,12.

5. The subscale "Locus control - Life" has a dynamics of lowering among students of the Republic of Dagestan (27.4) than among students of the Rostov Region (28.4).

The orientation of the students' activity vector, its worldview coloring, and semantic saturation give interaction of a multicultural space a definite constructive or destructive content. It is shown that the modern world is characterized by a tendency towards globalization and integration, and, accordingly, the educational environment for the system of higher professional education should be based on the principle of "cultural identity", the use of cultural resources, assimilation of human achievements represented in the sociocultural situation of student development.

It is proved in the research that the psychologically safe, "cultural-like" educational environment of higher education can contribute to the ethno-cultural competence development of the student's personality, increase the level of communicative and mediative abilities, and contribute to the student development.

The data obtained as a result of applying the SLO test correlate with the distinguished structure of value orientations among students at Rostov-on-Don and Makhachkala, and also generally reflect the characteristics of student age with its aspiration for the future and activity in terms of modeling their own lives. The absence of significant differences indicates the general development trends of the student's modern personality.

The results obtained, obviously, reflect the peculiarities of accents in socialization, associated primarily with ethnic characteristics. According to Dagestan tradition, the importance of self-control is emphasized in the development of the personality, the attitude is not formed that the person should control his emotions, behavior and selectivity of relations. Here historically determined is the desire to control own activity.

At the same time, it should be noted that in the field of family relations the expressed generation remains a priority for the older generation, while in the modern Russian family equality is declared to a greater extent. At the same time, the differences shown are not decisive and lie in the continuum of general trends and characteristics of modern youth.

\section{Conclusion}

Thus, against the background of similar or coincident results of the "result of life" and "locus-control of I", differences are distinguished in terms of understanding the goal in life, its meaningfulness, and the ability to manage the events of one's own life.

The data obtained using the SLO test were subjected to statistical processing by applying the Mann-Whitney test; the obtained value of Uemp (17) is in the zone of insignificant error.

To confirm or refute the hypothesis "Differences or similarities in instrumental values" for the groups of students (Makhachkala, Rostov-on-Don), the statistical Student's t-test criteria was used. The obtained empirical value $t(0)$ is in the zone insignificance. Significant differences between the results on instrumental values were not found for groups of students from Makhachkala and Rostov-on-Don.

The obtained empirical value of $t(0.8)$ is in the zone of insignificance, which indicates that there are no statistically significant differences in the answers of students living in different regions. The differences demonstrated by students at a number of indicators can be defined as trends, against the background of a general picture of the ideas similarity and value-semantic characteristics severity and development level of various components for subjective control. For the successful attitudes development of intolerance towards aggression, extremism and terrorism students, it is important to know the characteristics of motivation for extremist forms of behavior. 
Here, the influence on the youth environment of informal associations for an extremist orientation is a great importance. In this regard, the development of constructive meanings and values among students, as motivators of the positive humanistic orientation of their activity, acquires special significance.

\section{References}

1. A.A. Vasiliev, The development of student's tolerant personality in the multicultural space of a university, Education and self-development, 2 (8), 161-166 (2008).

2. V.P. Borisenkov, O.V. Gukalenko, A.Ya. Danilyuk, Multicultural educational space of Russia: history, theory, design basics (Pedagogy, Moscow, 2006).

3. Yu.V. Bykhovets, M.A. Padun, Personal anxiety and regulation of emotions in the context of the post-traumatic stress study, Clinical and special psychology, 8 (1), 78-89 (2019).

4. E.N. Dymova, N.V. Tarabrina, N. E. Kharlamenkova, Psychological safety and traumatic experience as modulators of the search for social support in a difficult life situation, Psychological Journal, 36 (3), 15-27 (2015).

5. M.A. Padun, Regulation of emotions and psychological well-being: individual, interpersonal, and sociocultural factors, Psychological Journal: Russian Academy of Sciences, 40 (3) 31-43 (2019).

6. L.S. Podymova, N.A., Podymov, E.A. Alisov, Readiness of teachers to ensure personal safety in an innovative educational environment, Integration of Education, 22 (4), 663-680 (2018). DOI: 10.15507 / 1991-9468.093.022.201804.663-680

7. M.N. Siraeva, Multicultural education of students - future teachers in a linguistic club, Abstract of thesis. ... cand. ped sciences (SPB., 2009).

8. N.E. Kharlamenkova, The concept of psychological safety and its justification from different scientific positions, Psychological journal: Russian Academy of Sciences, 40 (1), 28-37 (2019).

9. N.E. Kharlamenkova, The subject psychology development in modern studies of the social support phenomenon, Psychological Journal, 39 (2) 25-36 (2018).

10. Y.P. Shabaev, A.P. Sadokhin, O.V. Labunova, N.N. Sazonova, Anthropological understanding of the city and the methodology of urban study, Monitoring of public opinion: economic and social changes, 3 (145), 248-267 (2018).

11. R. M. Shamionova, M. V. Grigoryevaa, A.V. Grigoryev, World Assumptions and Youth Identity as Predictors of Social Activity Preferences, Psychology in Russia: State of the Art, 12 (2), 115 - 133 (2019). 